\title{
First report of Sydowia polyspora causing disease on Pinus pinea shoots
}

\author{
Ana Cristina Silva ${ }^{1}$ (D) | Joana Henriques ${ }^{1}$ (D) | Eugénio Diogo ${ }^{1}$ (D) | Ana Paula Ramos Jid $^{2,3}$ | \\ Helena Bragança ${ }^{1}$
}

${ }^{1}$ Unidade de Investigação e Serviços de Sistemas Agrários e Florestais e Proteção das Plantas, Instituto Nacional de Investigação Agrária e Veterinária, I.P., Oeiras, Portugal

${ }^{2}$ LEAF, Linking Landscape, Environment, Agriculture and Food, Instituto Superior de Agronomia, Universidade de Lisboa, Lisbon, Portugal

${ }^{3}$ LPPVA-Laboratório de Patologia Vegetal "Veríssimo de Almeida", Instituto Superior de Agronomia, Universidade de Lisboa, Lisbon, Portugal

\section{Correspondence \\ Helena Bragança, Unidade de Investigação e Serviços de Sistemas Agrários e Florestais e Proteção das Plantas, Instituto Nacional de Investigação Agrária e Veterinária, I.P., 2780-159 Oeiras, Portugal. \\ Email: helena.braganca@iniav.pt}

Editor: H. Tuğba Doğmuş-Lehtijärvi

\begin{abstract}
The fungus Sydowia polyspora is frequently isolated from conifers worldwide and is considered a pathogen on several hosts. Stone pine (Pinus pinea) is one of the most important forestry species throughout the Mediterranean basin due to the value of the edible pine nut. Stone pines showing tip dieback, needles with tan- to yellowcoloured lesions and shoot death, observed in stands in Portugal, were sampled for analysis. Fungal colonies covered with cream-coloured spore masses, were consistently obtained. Morphological and phylogenetic analyses of the ITS rDNA region enabled identification of these isolates as S. polyspora. Inoculation tests showed that the fungus caused lesions on excised $P$. pinea shoots. The symptoms observed might have a negative effect on pine nut production, and thus, evaluation of the impact of this disease is of relevance to future research. This paper is the first to report S. polyspora causing disease on $P$. pinea.
\end{abstract}

\section{KEYWORDS}

CSNN, Hormonema dematioides, Portugal, shoot necrosis

\section{1 | INTRODUCTION}

Stone pine (Pinus pinea L.) is amongst the most important forestry species in Portugal and throughout the Mediterranean basin. Pinus pinea has an important economic role in regions where it is planted, due to valuable edible pine nut. Pinus pinea is broadly considered a robust species, but unfortunately, in recent years, pine nut production has decreased, due to several factors including pests and diseases (Mutke et al., 2017).

The fungus Sydowia polyspora (Bref. \& Tavel) E. Müller (anamorph: Hormonema dematioides Lagerb. \& Melin) is frequently associated with current season needle necrosis (CSNN) on conifer species, particularly Abies spp. and Pinus sp., across Europe and North America (Talgø et al., 2010; Tinivella, Dani, Minuto, \& Minuto, 2014). The main symptoms on fir include tan- to yellow-coloured bands or spots, turning reddish brown during the summer. Entire needles may become necrotic and abscise (Talgø et al., 2010).
Similar symptoms caused by S. polyspora are reported on Pinus spp. Pan et al. (2018) verified that S. polyspora was able to infect Pinus yunnanensis Franch. in Southwestern China, causing chlorotic and reddish brown coloured lesions on needles, randomly distributed amongst otherwise healthy needles. Extensive leaf yellowing and scorching on Pinus halepensis Mill. was also observed in Italy (Tinivella et al., 2014).

Sydowia polyspora is also considered endophytic, being present in asymptomatic plants and in seeds (Cleary et al., 2019; Ridout \& Newcombe, 2018). However, some authors suggested that the fungus may become pathogenic in a colonized host, under the influence of certain abiotic and biotic factors (Ridout \& Newcombe, 2018; Talgø et al., 2010).

The aim of the present study was to investigate the causal agent of shoot dieback observed on P. pinea trees in Portuguese stands. This work is the first to report S. polyspora causing stem necrosis on $P$. pinea shoots. 


\section{2 | MATERIAL AND METHODS}

Samples from symptomatic stone pine trees of different ages, showing shoot tip dieback, needles with tan- to yellow-coloured lesions and shoot death, mainly found on the upper part of the canopy, were collected from P. pinea orchards across the Portuguese mainland. After macro- and microscopic observations of the sampled material, small pieces from the leading edge of the lesions were surface sterilized for $1 \mathrm{~min}$ in $1 \% \mathrm{NaOCl}$ and plated onto potato dextrose agar (PDA) amended with $0.5 \mathrm{mg} / \mathrm{ml}$ streptomycin sulphate to suppress bacterial growth. Cultures were incubated for seven days in $12 \mathrm{hr}$ light period at $25 \pm 100^{\circ} \mathrm{C}$. Hyphal tips of fungi emerging from tissue pieces were transferred to PDA, and single-spore cultures were produced. The resulting isolates were grown on PDA at $25 \pm 1^{\circ} \mathrm{C}$ in dark. Colony and conidial morphologies were recorded. Conidia were mounted in water and dimensions measured at $400 \times$ using an Olympus BX51 compound microscope and the program Olympus DP-Soft. For each isolate, length and width of 30 conidia were measured and the shape recorded. Isolates were deposited in the public collection of INIAV Institute (Micoteca da Estação Agronómica Nacional-MEAN), as MEAN1024, MEAN1025, MEAN1027, MEAN1029, MEAN1030 and MEAN1031.

To further confirm the morphological identification, sequence data of the internal transcribed spacer of the ribosomal DNA (ITS
rDNA) region were analysed. Genomic DNA was extracted from fresh mycelium using the "DNA, RNA and Protein PurificationNucleoSpin Plant II" kit (Macherey-Nagel-MN) following the manufacturer's instructions. The ITS rDNA region (ITS1-5.8S-ITS2) was amplified using the universal primer pair ITS5 and ITS4. PCR products were sequenced in both directions at STABVida Sequencing Laboratory (Caparica, Portugal) on a DNA analyser ABI PRISM $3730 x \mathrm{l}$ (Applied Bio systems) using the same primers as those used for the amplification reactions. The resulting nucleotide sequences were edited using the FinchTV version 1.4.0 (Geospiza Inc.) and BioEdit version 7.2.6 software, and a consensus sequence was obtained using the forward and reverse sequences. A BLAST engine search was used to determine sequence similarities in GenBank (NCBI-National Centre for Biotechnology Information). The most similar as well as some outgroup sequences were selected from the NCBI database and aligned using BioEdit version 7.2.6. Phylogenetic analysis was carried out using MEGA 6. Phylogenetic trees were constructed based on maximum likelihood method following the analysis of best-fit models using Bayesian information criterion (the Kimura 2-parameter model using a discrete Gamma distribution), and with 1,000 bootstrap replicates. Sequences obtained in this study were deposited in GenBank (accession numbers: MH198270, MH198271, MH198273, MN103808, MN103809, MN103810). (a)

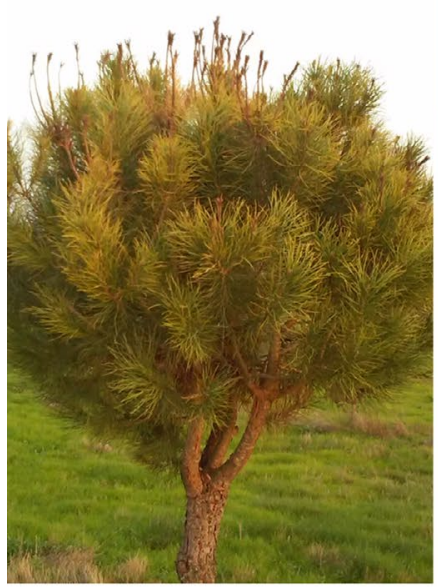

(d)

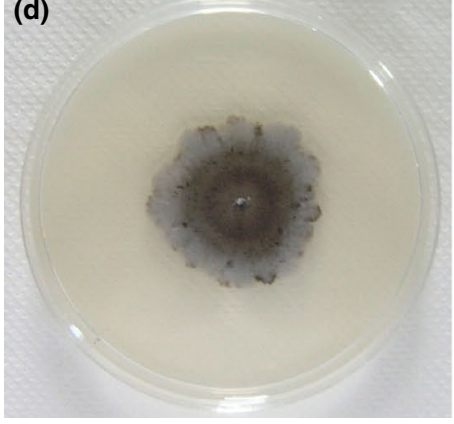

(b)

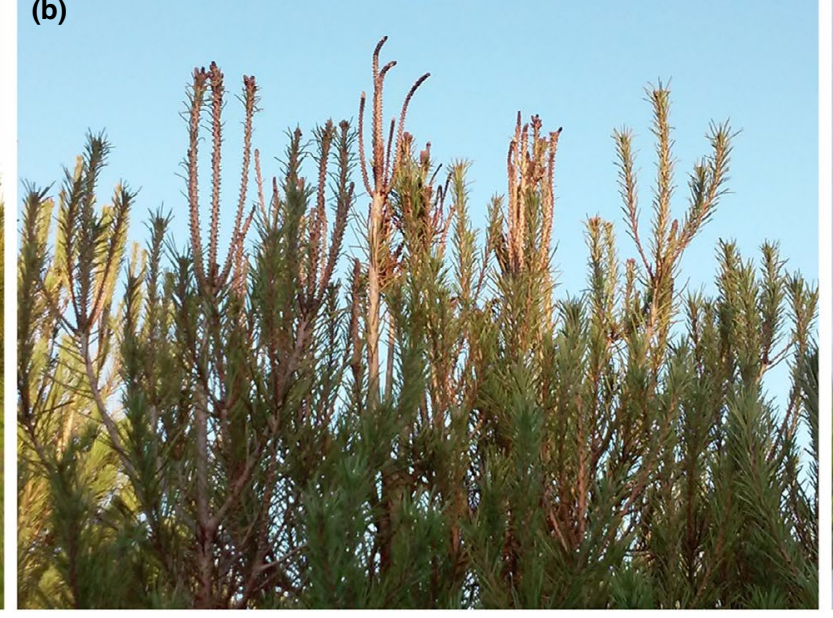

(e)

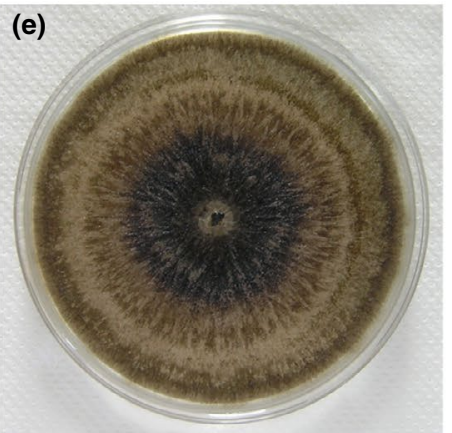

(f)

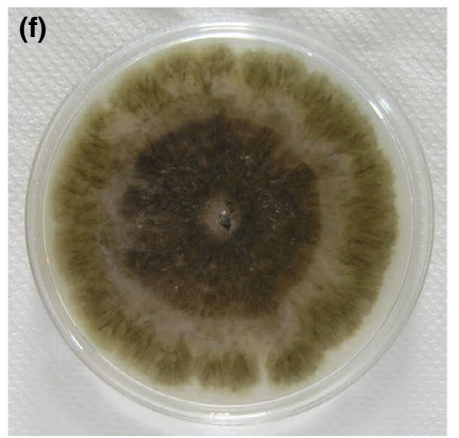

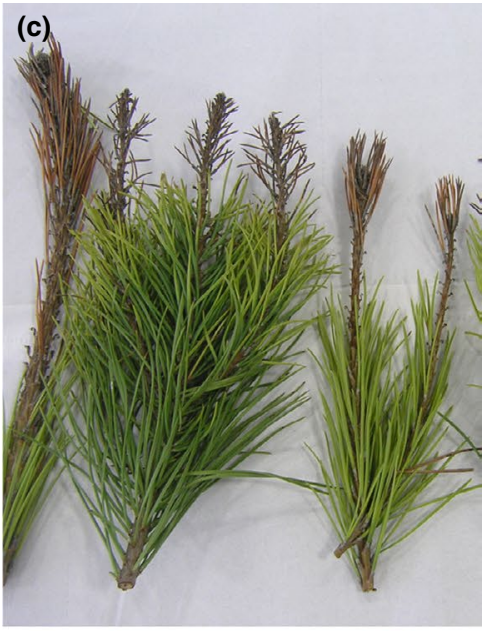

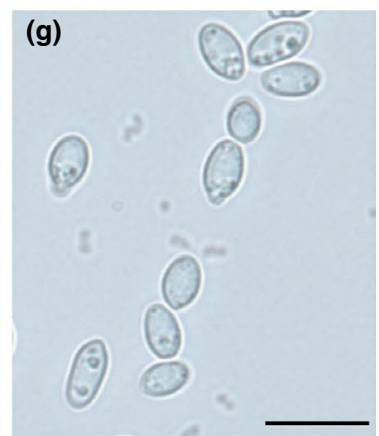

FIGURE 1 Symptoms observed on Pinus pinea and morphological characters of Sydowia polyspora isolates. (a) Symptomatic stone pine tree. (b) Diseased shoots in the upper part of the canopy. (c) Diseased shoots collected in field. (d-f) Colonies on PDA after 10 days at $25^{\circ} \mathrm{C}$ in dark, isolates MEAN1029, MEAN1030 and MEAN1031. (g) Conidia. Scale bar: $10 \mu \mathrm{m}$ 
FIGURE 2 Molecular phylogenetic analysis of ITS sequences of Sydowia polyspora isolates by maximum likelihood method. The evolutionary history was inferred by using the maximum likelihood method based on the Kimura 2-parameter model using a discrete Gamma distribution with 1,000 bootstrap replicates. The tree with the highest log likelihood (-1463.3032) is shown. The percentage (above $70 \%$ ) of trees in which the associated taxa clustered together is shown next to the branches. All positions with $<95 \%$ site coverage were eliminated. There were a total of 469 positions in the final dataset. The scale bar represents the expected number of changes per site. Bold-type indicates sequences obtained in this study. Sequences obtained from databases are identified with its reference number and isolates code. The tree is rooted to Pseudosydowia eucalypti (CPC 14028; CPC 14927)

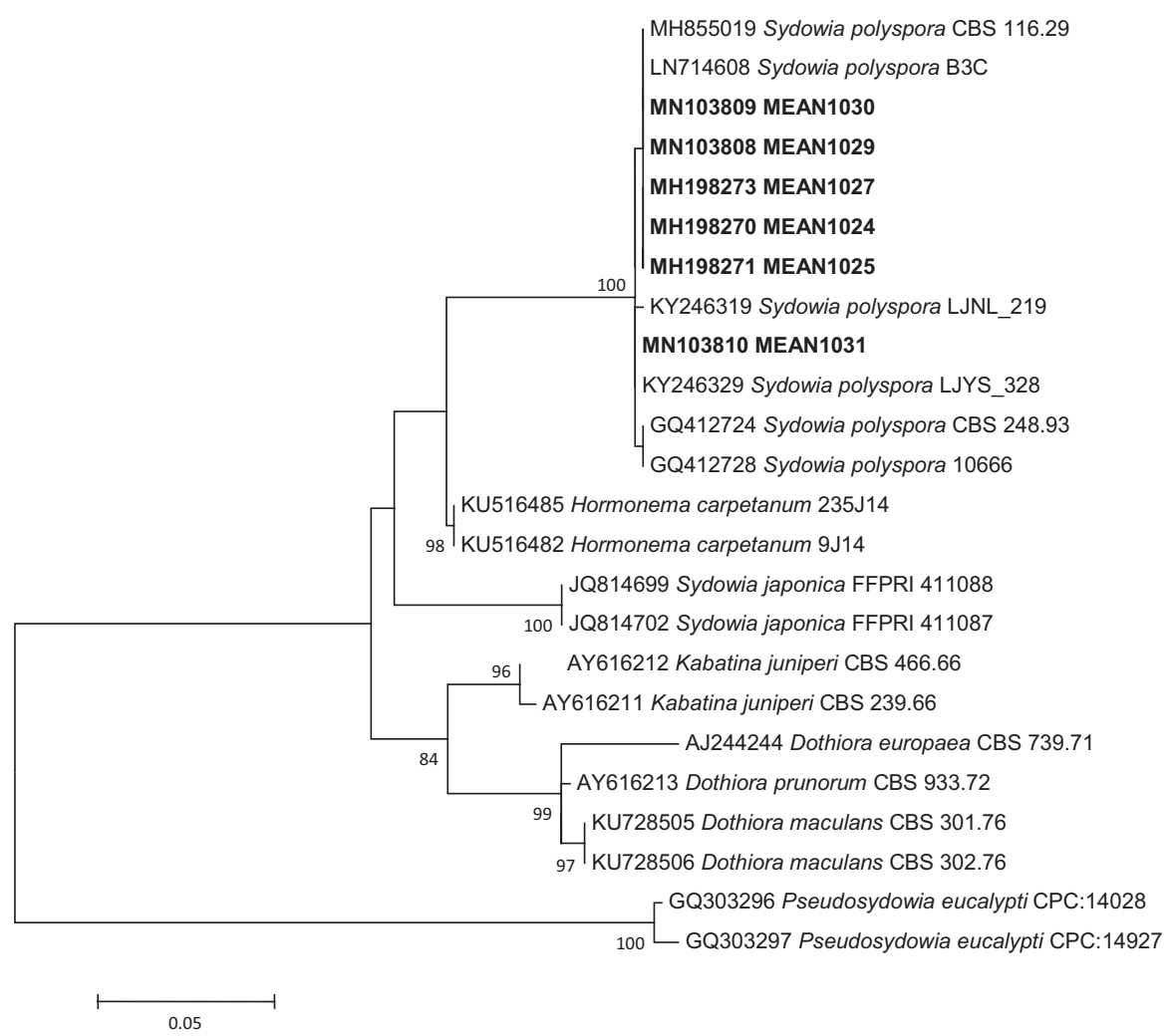

In order to test the pathogenicity of $S$. polyspora isolates on stone pine, inoculation was performed following a method based on Pan et al. (2018). Three isolates, from different geographic origins, were randomly selected (MEAN1029, MEAN1030, MEAN1031). Colonies were grown on PDA in 9-cm plastic Petri dishes for 10 days in the dark at $25^{\circ} \mathrm{C}$. Inoculation was performed on healthy pine shoots (length $30 \pm 5 \mathrm{~cm}$ ) collected from a stone pine stand in Oeiras, Portugal, in May 2019. A total of 24 excised shoots were used. Each isolate was inoculated in six shoots, and the control treatment also included six shoots. A wound was made on the surface of each shoot, and an agar plug of approximately $5 \mathrm{~mm}^{2}$ was placed between the phloem and the bark. Control treatment used sterile PDA plugs. After inoculation, the wounds were wrapped with sterilized moist cotton wool and sealed with Parafilm for seven days. Pine shoots were maintained at $20^{\circ} \mathrm{C}$ in plastic beakers ( $500 \mathrm{ml}$ volume) filled with tap water. After 28 days, lesion extension was assessed and re-isolation performed. For each shoot, three pieces of phloem $\left(5 \mathrm{~mm}^{2}\right)$ collected from the edge of the necrotic area were cultured on PDA and incubated at $25^{\circ} \mathrm{C}$ for 7 days in the dark.

\section{RESULTS AND DISCUSSION}

Colonies covered with cream-coloured spore masses were consistently obtained from $P$. pinea diseased shoots (Figure 1). Colonies reached $40-80 \mathrm{~mm}$ diameter after 10 days at $25^{\circ} \mathrm{C}$ in dark, with white margins, later becoming brown, presenting non septate, ellipsoid, hyaline and multiguttulate spores $(\dot{x} \pm$ S.D. $=6.79 \pm 1.31 \times 3.68 \pm 0.72 \mu \mathrm{m}[n=180])$. These morphological characteristics were consistent with those reported for S. polyspora (Talgø et al., 2010).

BLAST analysis of the ITS sequences confirmed the identification of the isolates, with $99 \%-100 \%$ similarity with previously reported sequences of $S$. polyspora. A phylogeny inferred based on ITS sequence data of isolates obtained in this study, along with 15 sequences retrieved from GenBank grouped the obtained sequences from $P$. pinea shoots in a clade along with other previously known S. polyspora strains (Figure 2).

In the inoculation tests, after 28 days, necrotic areas extending beyond the inoculated points were observed on the phloem of all shoots treated with strain MEAN1030. In controls and with the other two isolates tested (MEAN1029 and MEAN1031), necrosis was observed only in the inoculation point, without further extension. The fungus was re-isolated successfully from the shoots inoculated with MEAN1030, thus confirming that S. polyspora was able to cause necrosis on excised stone pine shoots. To our knowledge, this report is the first to describe $S$. polyspora as a casual agent of $P$. pinea shoot disease.

Two of the three isolates used in the inoculation tests did not cause necrosis on the shoots. Pan et al. (2018) also verified different degrees of symptoms development on needles of $P$. yunannensis inoculated with different $S$. polyspora strains, when four of the ten strains tested caused no symptoms. In addition, Talgø et al. (2010) verified no symptom development in one of the three tests performed with the same strains, thus, suggesting that diverse abiotic and biotic 
factors can play an important role in the development of the disease, either by affecting the ecology of the pathogen or the susceptibility of the host. Moreover, Cleary et al. (2019) recently found S. polyspora in asymptomatic seeds of several Pinus spp. obtained across Europe and North America, including P. pinaster, P. radiata, P. strobus, $P$. sylvestris, $P$. mugo from Portugal and $P$. pinea from Turkey. These findings emphasize the need to develop better understanding of the pathways of dissemination and interactions between the fungus and its hosts. One possible agent involved in vectoring the fungus and/ or driving host stress could be the insect Leucaspis sp. (Hemiptera: Diaspididae) since some stands with symptomatic shoots had large numbers of this insect. Sydowia polyspora was also found to be the dominant fungal species carried by insects (Tomicus spp.) feeding on pine shoots, although the fungus-insect-plant interaction remains unclear (Muñoz-Adalia et al., 2017).

The necrotic shoots in the upper part of the canopy of $P$. pinea are especially concerning, since the symptoms may compromise development of the pine cones and consequently the production of pine nuts, causing economic losses for this species, which should be evaluated with additional research. Further work is underway to understand the pathways and biotic and/ or abiotic factors that contribute to disease expression in the Portuguese $P$. pinea forest.

\section{ACKNOWLEDGEMENTS}

This work was partly supported by INIAV Institute and ISA, University of Lisbon. The authors also acknowledge Dr. Filomena Nóbrega for Laboratory facilities.

\section{ORCID}

Ana Cristina Silva (iD https://orcid.org/0000-0003-4730-3415 Joana Henriques (iD https://orcid.org/0000-0002-2045-8954

Eugénio Diogo (iD https://orcid.org/0000-0002-4127-9525

Ana Paula Ramos (iD https://orcid.org/0000-0001-5974-7481

Helena Bragança (iD https://orcid.org/0000-0002-7957-5493

\section{REFERENCES}

Cleary, M., Oskay, F., Doğmuş, H. T., Lehtijärvi, A., Woodward, S., \& Vettraino, A. M. (2019). Cryptic risks to forest biosecurity associated with the global movement of commercial seed. Forests, 10(5), 459. https://doi.org/10.3390/f10050459

Muñoz-Adalia, E. J., Sanz-Ros, A. V., Flores-Pacheco, J. A., Hantula, J., Diez, J. J., Vainio, E. J., \& Fernández, M. (2017). Sydowia polyspora dominates fungal communities carried by two Tomicus species in pine plantations threatened by Fusarium circinatum. Forests, 8, 127. https://doi.org/10.3390/f8040127

Mutke, S., Calama, R., Nasrallah Neaymeh, E., \& Roques, A. (2017). Impact of the dry cone syndrome on commercial kernel yield of stone pine cones. In I. Carrasquinho, A. C. Correia \& S. Mutke (Eds.), Mediterranean pine nuts from forests and plantations (pp. 79-84). Zaragoza: CIHEAM. (Options Méditerranéennes : Série A. Séminaires Méditerranéens; $n$. 122).

Pan, Y., Ye, H., Lu, J., Chen, P., Zhou, X., Qiao, Q., \& Yu, Z. (2018). Isolation and identification of Sydowia polyspora and its pathogenicity on Pinus yunnanensis in Southwestern China. Journal of Phytopathology, 166, 386-395. https://doi.org/10.1111/jph.12696

Ridout, M., \& Newcombe, G. (2018). Sydowia polyspora is both a Foliar endophyte and a preemergent seed pathogen in Pinus ponderosa. Plant Disease, 102, 640-644. https://doi.org/10.1094/ PDIS-07-17-1074-RE

Talgø, V., Chastagner, G., Thomsen, I. M., Cech, T., Riley, K., Lange, K., ... Stensvand, A. (2010). Sydowia polyspora associated with current season needle necrosis (CSNN) on true fir (Abies spp.). Fungal Biology, 114, 545-554. https://doi.org/10.1016/j.funbio.2010.04.005

Tinivella, F., Dani, E., Minuto, G., \& Minuto, A. (2014). First report of Sydowia polyspora on Aleppo Pine (Pinus halepensis) in Italy. Plant Disease, 98(2), 281. https://doi.org/10.1094/PDIS-06-13-0658-PDN

How to cite this article: Silva AC, Henriques J, Diogo E, Ramos AP, Bragança H. First report of Sydowia polyspora causing disease on Pinus pinea shoots. For Path. 2020;50:e12570. https://doi.org/10.1111/efp.12570 